\title{
СИНТЕЗ И ПРОТИВООПУХОЛЕВЫЕ СВОЙСТВА ПИРИДОКСИНСОДЕРЖАЩИХ АНАЛОГОВ ХАЛКОНОВ
}

\section{О.В. Бондарь, Р.С. Павельев, С. Алрхмун, И.И. Рахмаев, М.В. Пугачев, Ю.Г. Штырлин}

Научно-образовательный центр фармацевтики, Казанский (Приволжский) федеральный университет, 420008, Россия, Казань, ул. Кремлевская, 18.

DOI: 10.19163/MedChemRussia2021-2021-449

E-mail: OkVBondar@kpfu.ru

Функционализация природных биологически активных соединений является одним из важнейших подходов к созданию новых лекарственных средств. Пиридоксинсодержащие халконы 6 и 7 получали по приведенной ниже схеме:<smiles>[R3]c1ccc(C(=O)CCl)c([R3])c1[R]</smiles><smiles>[R3]c1ccc(C(=O)C[PbH2+][B-])c([R3])c1[R]</smiles>
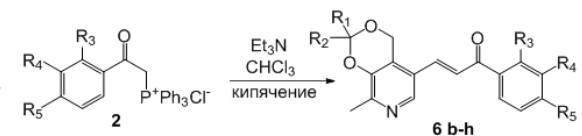<smiles>Cc1[nH+]cc(CO)cc1CO</smiles><smiles>[R]C1([R])OCc2c(C=O)nc(C)c(O)c2CO1</smiles><smiles>[R3]c1ccc(C(=O)C[PbH2]Cl)c([R3])c1[R]</smiles><smiles>[R3]c1ccc(C(=O)/C=C/c2nc(C)c(O)c3c2COC([R2])([R])OC3)c([R3])c1[R3]</smiles>

a) $R_{1}=R_{2}=R_{4}=H, R_{3}=R_{5}=C l$; $) R_{1}=R_{2}=C_{3}, R_{4}=H, R_{3}=R_{5}=\mathrm{Cl}$; c) $\mathrm{R}_{1}=\mathrm{R}_{4}=\mathrm{H}, \mathrm{R}_{2}=\mathrm{C}_{2} \mathrm{H}_{5}, \mathrm{R}_{3}=\mathrm{R}_{5}=\mathrm{Cl}$; d) $\mathrm{R}_{1}=\mathrm{R}_{4}=\mathrm{H}, \mathrm{R}_{2}=\mathrm{C}_{3} \mathrm{H}_{7}, \mathrm{R}_{3}=\mathrm{R}_{5}=\mathrm{Cl}$; e) $\mathrm{R}_{1}=\mathrm{R}_{4}=\mathrm{H}, \mathrm{R}_{2}=\mathrm{i}-\mathrm{C}_{3} \mathrm{H}_{7}, \mathrm{R}_{3}=\mathrm{R}_{5}=\mathrm{Cl}$; f) $\mathrm{R}_{1}-\mathrm{R}_{2}=$ spiro $-\mathrm{C}_{4} \mathrm{H}_{8}, \mathrm{R}_{4}=\mathrm{H}, \mathrm{R}_{3}=\mathrm{R}_{5}=\mathrm{Cl}$; g) $\mathrm{R}_{1}=\mathrm{R}_{4}=\mathrm{H}, \mathrm{R}_{2}=\mathrm{CH}\left(\mathrm{CH}_{3}\right) \mathrm{C}_{9} \mathrm{H}_{19} ; \mathrm{R}_{3}=\mathrm{R}_{5}=\mathrm{Cl}$; h) $\mathrm{R}_{1}=\mathrm{R}_{2}=\mathrm{CH}_{3}, \mathrm{R}_{3}=\mathrm{H}, \mathrm{R}_{4}=\mathrm{R}_{5}=\mathrm{OH}$ i) $R_{1}=R_{2}=R_{3}=H, R_{4}=R_{5}=O H$

По данным исследований in vitro на шести опухолевых клеточных линиях из коллекции АТСС соединения 6h и 7h проявляют наиболее высокую противоопухолевую активность, значения $\mathrm{IC}_{50}$ которых варьируются в интервале 1,5 - $10 \mu \mathrm{M}$. Соединения $6 \mathbf{h}$ и $\mathbf{7 h}$ незначительно уступают по эффективности доксорубицину, но при этом превосходят его по показателю индекса селективности в 4 раза. Соединения $6 \mathrm{~h}$ и $7 \mathrm{~h}$ также обладают антиоксидантной активностью сопоставимой с действием аскорбиновой кислоты, ингибируют перекисное окисление липидов в тесте с лецитиновыми липосомами и тиобарбитуровой кислотой, а также ингибируют окислительный стресс клеток.

Исследуемые соединения представляют интерес для разработки лекарственных средств для лечения социально значимых заболеваний.

Работа выполнена за счет средств субсидии, выделенной Казанскому федеральному университету для выполнения проектной части государственного задания в сфере научной деятельности №0671-2020-0053.

$$
-449-
$$

